\title{
Healthy diet associated with better asthma outcomes in elderly women of the French Asthma-E3N study
}

\author{
Wassila Ait-hadad ${ }^{1} \cdot$ Annabelle Bédard $^{1} \cdot$ Sébastien Chanoine ${ }^{2} \cdot$ Orianne Dumas $^{1} \cdot$ Nasser Laouali $^{3}$. \\ Nicole Le Moual ${ }^{1}$. Bénédicte Leynaert ${ }^{1}$. Conor Macdonald ${ }^{3} \cdot$ Valérie Siroux $^{2} \cdot$ Marie-Christine Boutron-Ruault $^{3}$ (D) \\ Raphaëlle Varraso ${ }^{1}$
}

Received: 16 June 2021 / Accepted: 19 January 2022 / Published online: 27 February 2022

(c) The Author(s) 2022

\begin{abstract}
Purpose The impact of a healthy diet on asthma prevention and management, particularly among elderly women, remains poorly understood. We investigated whether a healthy diet would be associated with fewer asthma symptoms, and, among women with asthma, with reduced uncontrolled asthma and metabolic-related multimorbidity.

Methods We included 12,991 elderly women (mean age $=63$ years) from the Asthma-E3N study, a nested case-control study within the French E3N cohort. Negative binomial regressions were used to analyse associations between a healthy diet [evaluated by the Alternate Healthy Eating Index-2010 (AHEI-2010)] and a validated asthma symptom score, and logistic regressions to analyse associations between the AHEI-2010 with the asthma control test and multimorbidity profiles previously identified by clustering methods on medications used.

Results After adjustment for potential confounders, a linear inverse association was found between the AHEI-2010 score and the asthma symptom score [mean score ratio $(95 \% \mathrm{CI})=0.82(0.75-0.90)$ for the highest versus lowest quintile; $p$ for trend $<0.0001]$. In addition, women in the highest versus lowest AHEI-2010 tertile were at a lower risk to belong to the "Predominantly metabolic multimorbidity-related medications profile" compared to the "Few multimorbidity-related medications" profile [OR $0.80(0.63-1.00)$ for tertile 3 ; $p$ for trend $=0.05 ; n=3474]$.

Conclusion Our results show that a healthy dietary intake could play an important role in the prevention and management of asthma over the life course.
\end{abstract}

Keywords Alternate Healthy Eating Index-2010 (AHEI-2010) · Asthma symptom score · Asthma control · Metabolic multimorbidity-related medications $\cdot$ Body mass Index $\cdot$ Asthma prevention $\cdot$ Asthma management

\section{Introduction}

Marie-Christine Boutron-Ruault

Marie-christine.BOUTRON@gustaveroussy.fr

1 Université Paris-Saclay, UVSQ, Univ. Paris-Sud, Inserm, Équipe d'Épidémiologie Respiratoire Intégrative, CESP, Villejuif, France

2 Team of Environmental Epidemiology Applied To Reproduction and Respiratory Health, Institute for Advanced Biosciences (IAB), Inserm U1209, CNRS, University Grenoble Alpes, Grenoble, France

3 Université Paris-Saclay, UVSQ, Univ. Paris-Sud, Inserm, Gustave Roussy, Équipe “Exposome Et Hérédité”, CESP, 94805 Villejuif, France
As recently underlined in the Lancet [1], given the immense societal and individual burden of asthma, there is an urgent need to further develop novel strategies to limit the disease and its consequences. Asthma control, the main objective of asthma management, remains suboptimal in roughly one asthma patient out of two, with even higher rates among women $[2,3]$. In this context, investigating the role of modifiable lifestyle factors such as diet is key for the primary and secondary prevention of this highly prevalent disease. While there are promising findings for possible dietary intervention to reduce asthma in children [4], the impact of diet on asthma in adults, and even more so among the elderly, remains largely unknown. 
Among adults over 65 years, the prevalence of asthma varied from 4 to $13 \%$ [5], a rate likely underestimated as it is frequently underdiagnosed in this age group [6]. The burden of asthma is more significant in the elderly than in their younger counterparts $[7,8]$ with more hospitalisations $[6,8]$, and worse health-related quality of life [5, $6,8]$ and asthma control [6]. Asthma in the elderly is a phenotype of interest, especially in women because asthma tends to be more prevalent ( $9.9 \%$ vs $6.2 \%)$ and more severe in women than in men [9]. Obesity is now an established risk factor for asthma $[10,11]$, with recent studies supporting the hypothesis that obesity is causally related to asthma [12], and with a higher risk in elderly women as compared to men [13]. Furthermore, multimorbidity is common in asthma patients, especially in the elderly [13]. Besides obesity, allergic rhinitis, chronic obstructive pulmonary disease (COPD), gastroesophageal reflux, and sleep apnoea syndrome that are the most common asthma-related multimorbidities, recent studies have suggested that other chronic conditions such as cardiovascular diseases (CVD), metabolic syndrome, or type 2 diabetes mellitus are also involved [14].

Although published studies on the diet-asthma association have traditionally focused on specific nutrients or foods, it is important in terms of dietary recommendations to emphasize overall dietary patterns rather than specific foods and nutrients to account for synergistic effects on health of foods and nutrients within the overall diet [15]. Several dietary scores have been proposed to globally assess diet quality and among them, the Alternate Healthy Eating Index-2010 (AHEI-2010) score, that reflects a healthy diet, has been associated with a lower risk of chronic diseases [16]. Among middle-aged women and men, a better adherence to a healthy diet evaluated by the AHEI-2010 was associated with a lower asthma symptom score [17, 18] and better asthma control [18]. Being a continuous measure of asthma, the asthma symptom score that has been associated with new onset of asthma, provides more power to detect risk factors for asthma as compared to a dichotomous definition [19]. Up to now, the role of a healthy diet on asthma symptoms, asthma control, and asthma-related metabolic and cardiovascular morbidities, which are commonly associated with both asthma [20] and an unhealthy diet [21], remains unknown among elderly women.

In a large study among elderly women, we aimed to investigate (1) the association between a healthy diet assessed with the AHEI-2010, and the asthma symptom score and, (2) among patients with asthma, the association of this dietary score with uncontrolled asthma and with specific metabolic and cardiovascular multimorbidityrelated medications profile.

\section{Methods}

\section{Study population}

The E3N study (Etude Epidémiologique auprès des femmes de la Mutuelle Générale de l'Education Nationale [MGEN]) is a prospective cohort which was initiated in 1990 to investigate risk factors of major non-communicable diseases in among 98,997 women affiliated to the a French national health insurance plan covering mostly teachers [22]. Since 1990, information on lifestyle and medical history has been collected approximately every 2 years by means of self-administered questionnaires.

Current analyses were conducted on women participating in the Asthma-E3N study, a nested case-control study on asthma within the E3N study, conducted in 2011. Briefly, 7,100 cases, e.g., women who gave a positive answer to the single question "Have you ever had an asthma attack?" in the main questionnaires at least once between 1992 and 2008, and 14,200 age-matched women without asthma, i.e., women who never reported any asthma attack between 1992 and 2008. Out of the 21,300 women invited to participate to the Asthma-E3N study, 19,404 women responded to the respiratory health questionnaire (91\% response rate) (Fig. 1). We excluded women who did not complete the food questionnaire in 1993 or in 2005 , or had an implausibly high (top $1 \%$ of the ratio between energy intake and energy requirement (EIER)) or low (bottom $1 \%$ of the EIER ratio) total energy intake in 1993 or in $2005(n=3708)$. For the asthma symptom score, we further excluded women who did not answer to the asthma symptom questions $(n=2705)$. For "multimedication" profiles, we first selected women who reported "ever asthma" ( $n=3474)$, and for asthma control, we further excluded women without current asthma $(n=1140)$. The analytic population included 12,991 women for the asthma symptom score, 2587 women for the asthma control, and 3474 women for the "multimedication" profiles.

Comparison of excluded vs included participants is presented in eTable 1. Excluded participants because of missing dietary data $(n=3708)$ were older than included participants $(n=12,991)$. After adjustment for age, excluded participants had a lower educational level, were less often married, and had more missing data for asthma outcomes, as compared to included women. When additionally excluding participants because of missing data for the asthma symptom score $(n=2705)$, excluded women were significantly older than included participants. After adjustment for age, excluded participants consumed slightly more energy intake, were less physically active, were more often current smokers, had a lower educational level, and were more often overweight or obese, as compared to included women. 

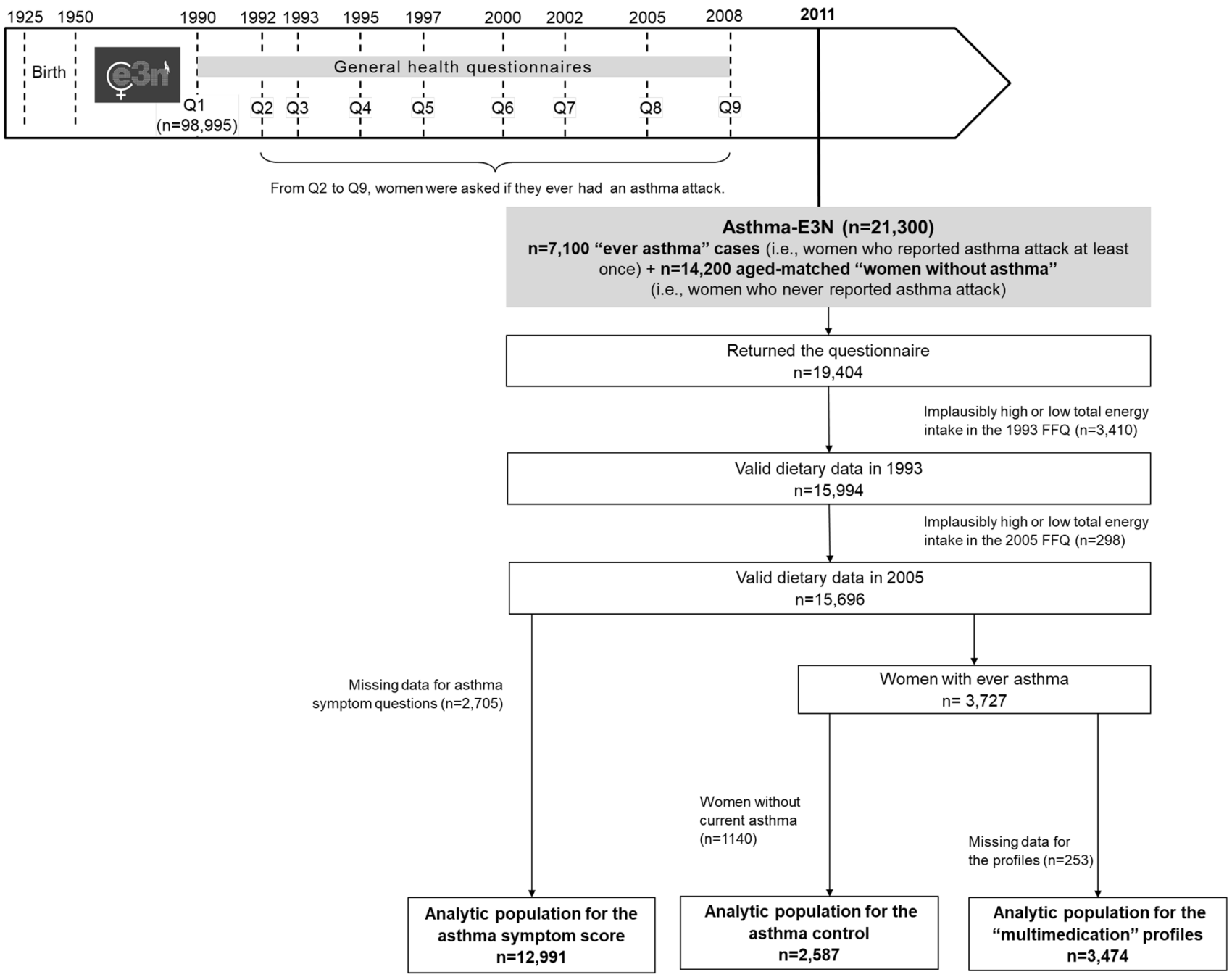

Fig. 1 Study design and flow chart of participants

The study protocol was approved by the French Institutional Ethics Committee, and all participants provided their written informed consents.

\section{Diet assessment}

We calculated the AHEI-2010 from two validated semiquantitative food history questionnaires administered in 1993 and 2005. The first part of the questionnaire was semi-quantitative and assessed consumption frequencies and portion sizes for the eight potential daily meals (breakfast, morning snack, aperitif before lunch, lunch, afternoon snack, pre-dinner aperitif, dinner, and after dinner snack) for 66 foods or food groups. Frequency was quantified in 11 potential categories: never or less than once a month; 1,2 , or 3 times a month, and 1 to 7 times a week. To facilitate the estimation of portion sizes, a photo booklet was also sent [23]. The second part of the questionnaire was qualitative and allowed detailing the consumption of specific foods within the food groups mentioned in the first part of the questionnaire.

The AHEI-2010 has been previously described [16]. It includes 11 items: 6 items considered as beneficial (vegetables, fruits, whole grains, nuts and legumes, long-chain $\Omega-3$ fatty acids, and polyunsaturated fatty acids); 1 item for which moderate consumption is recommended (alcohol); and 4 items for which avoidance or low consumption is considered best (sugar-sweetened beverages and fruit juices, red/processed meat, trans fat, and sodium). In our study, we calculated a modified AHEI-2010 including all items except trans fat, which was not available. The total score ranged from 0 to 100 , a higher score representing a healthier diet. When the sample size allowed it, we categorized the AHEI-2010 score in quintiles, otherwise in tertiles. 


\section{Asthma outcome assessment}

The asthma symptom score has been previously proposed as a validated continuous measure of asthma in epidemiological studies [24, 25]. It is particularly relevant in epidemiological studies, as it can be used in participants both with and without asthma allowing integration of different asthma phenotypes and different levels of asthma prevention. It ranges from 0 to 5 according to the presence or absence of five respiratory symptoms during the past 12 months.

To assess asthma control, we used the asthma control test (ACT), a validated self-administered questionnaire based on five questions on activity limitations, frequency of symptoms, and frequency of use of quick-relief medication in the past 4 weeks [26]. The total ACT score ranges from 5 to 25 and we categorised asthma as controlled (ACT $>19$ ) versus uncontrolled (ACT $\leq 19)$ [26]. Due to the large sample size, we further distinguished participants with a score of 25 and participants with a score of 20-24, as previously done [27]. Asthma control was therefore classified as: controlled asthma (ACT score $=25$ ), partly controlled asthma (ACT score between 20 and 24), and poorly controlled asthma (ACT score $\leq 19)$ [26].

Multimorbidity-related medication profiles in asthma were identified using latent class analysis (LCA) based on data from the exhaustive MGEN drug database, and personal characteristics (body mass index, sleep apnoea syndrome and smoking status), as previously described in detail [28]. Briefly, non-hospital-delivered drug classes were identified over the 2 years before the Asthma-E3N questionnaire from the exhaustive MGEN drug reimbursement database using the Anatomical Therapeutic Chemical (ATC) code. Latent class analyses (LCA), i.e. a data-driven approach, were performed to identify asthma groups characterised by specific multimorbidity-related medication profiles. Te following three profiles were identified: (1) the "Few multimorbidityrelated medications" profile, (2) the "Predominantly allergic multimorbidity-related medications", and (3) "Predominantly metabolic multimorbidity-related medications".

\section{Covariates}

Self-administered questionnaires were used to collect data on socio-demographic and lifestyle characteristics. Energy intake was computed in 1993 and 2005 using a Food Composition Database derived from the French Information Center on Food Quality (CIQUAL) and expressed in kilocalories/ day (kcal/day) [29]. Physical activity was assessed in 2005 using data from several questions on different activities [30] and expressed in metabolic equivalent of tasks (METs) per week (MET-hours/week). Smoking status, assessed in 2005, was categorized into the following three classes: never, former, or current smoker. Educational level ( $<$ high school diploma, high school to 2-level university, 3- to 4-level university, $\geq 5$-level university) was collected in 1992 and marital status (married or not) was collected in 1990. Having farmer parents was collected in 2007 [31].

Body Mass Index (BMI), based on self-reported current weight and height and expressed in $\mathrm{kg} / \mathrm{m}^{2}$, was calculated in 2005 with the "last observation carried forward" method to take care of missing data, and analysed as a continuous variable or three categories: $<20$ [low weight, 20-25 (normal weight) and $\geqslant 25 \mathrm{~kg} / \mathrm{m}^{2}$ (overweight/obesity) using the WHO cut-off for overweight/obesity [32].

\section{Statistical analysis}

Since the asthma symptom score is a count outcome ranging from 0 to 5 , with an excess of zero counts, the strength of the association between the average of the AHEI-2010 score (quintiles) and the asthma symptom score (count) was estimated by using negative binomial regression [33] expressed as mean score ratios (MSRs) and 95\% confidence intervals (95\% CI). Change in the asthma score is reported for an increase/decrease of 1 category (tertile or quintile) in the AHEI-2010 diet score. Our main model was adjusted for age, energy intake, leisure-time physical activity, smoking status, education level, marital status, and having farmer parents. To account for the study case-control design, models were further adjusted for ever asthma; we also performed a stratified analysis on asthma status, and tested the interaction between quintiles of AHEI-2010 and ever asthma.

Among participants with asthma, associations between tertiles of the AHEI-2010 with uncontrolled asthma (binary outcome) and multimorbidity-related medications profiles (multicategorical outcome) were evaluated by binary logistic and multinomial logistic regressions adjusted for age, energy intake, leisure-time physical activity, smoking status, education level, marital status, and having farmer parents. To handle missing data on ACT $(n=729)$, multiple imputation was performed, as previously reported [34]. The PROC MI SAS procedure was used to perform 20 imputations. We conducted several sensitivity analyses for ACT: (1) using non-imputed data, (2) considering asthma control in three categories (eTable 2), and (3) further adjusting for multimorbidity-related medication profiles.

As obesity is a major risk factor for asthma [35] and healthy diet directly affects obesity [36], it can be hypothesized that obesity acts as a mediator rather than a confounder in the diet-asthma association [37]; therefore, models were not adjusted for BMI. To evaluate effect modification by BMI in the diet-asthma association, we performed sensitivity analyses stratified on BMI and tested the statistical significance of the interaction term. In addition, we used generalized structural equation modeling (SEM), an exploratory approach that enables to test the existence of the 
hypothesized relationships (i.e. "paths") between diet, BMI, and the asthma symptom score (eFigure 1) and between diet, BMI, and asthma control (eFigure 2), while controlling for potential confounders [38], using the gsem command in STATA. The association of the BMI with the AHEI-2010 was obtained by linear regression model and measured by the difference in the expected BMI $(\beta)$ according to quintiles or tertiles of the AHEI-2010; associations between BMI and the AHEI-2010 with the asthma symptom score were obtained by negative binomial regression models, and with asthma control through logistic regression models. As obesity is one of the factors included in the LCA to derive the multimorbidity-related medication profiles, we did not stratify on BMI nor apply SEM for this outcome.

To account for potential residual confounding by smoking (never smokers, ex-smokers, current smokers), we also conducted stratified analyses on the smoking status, and tested the statistical significance of interaction term.

The test for trend across AHEI-2010 categories was calculated using quintile or tertile median values.

All tests were two-sided and $p$ values $<0.05$ were considered statistically significant. Analyses were conducted using SAS version 9.4 (SAS Institute, Cary, NC, USA) or STATA version 14.

\section{Results}

\section{Participant characteristics}

Participant characteristics are shown in Table 1 according to quintiles of the AHEI-2010. Women were aged 63 years on average. Women in the highest quintile of the AHEI-2010 (i.e., healthier diet) were older than those in the lowest quintile (i.e., unhealthier diet). After adjustment for age, women in the highest quintile of the AHEI-2010 consumed fewer calories, were more physically active, less likely to be current smokers, had more often farmer parents, and were less often overweight or obese, as compared to women in the lowest quintile of the AHEI-2010.

\section{Association between the AHEI-2010 and the asthma symptom score}

Thirty-nine percent of women reported at least one asthma symptom. After adjustment for age (Table 2), women with higher AHEI-2010 scores had lower asthma symptom scores with MSRs $(95 \% \mathrm{CI})$ of $0.91(0.83-0.99)$ for quintile 2 (Q2), $0.85(0.78-0.93)$ for quintile $3(\mathrm{Q} 3), 0.86(0.79-0.94)$ for quintile $4(\mathrm{Q} 4)$, and $0.77(0.71-0.85)$ for quintile 5 (Q5) as compared with the first quintile ( $p$ trend $<0.001$ ). After adjustment for potential confounders (model 2), the association remained of similar magnitude. Further adjustment for ever asthma led to a similar result (model 3).

In analyses stratified on BMI, MSRs remained below one in each category, and the interaction term between the AHEI-2010 and BMI was not statistically significant (Fig. 2) ( $p$ for interaction $=0.14$ ). Using SEM, we still reported a negative association between the AHEI-2010 and the asthma symptom score, as well a significant negative dose-response relationship between the AHEI-2010 and BMI and a significant positive association between BMI and the asthma symptom score (eFigure 1).

In analyses stratified on smoking status, associations remained statistically significant and of similar magnitude in each category (Fig. 2) ( $p$ for interaction $=0.98$ ). Finally, when analyses were stratified according to the asthma status, similar associations were reported between the AHEI-2010 and the asthma symptom score among women with or without self-reported ever asthma ( $p$ for interaction $=0.22$ ).

\section{Association between AHEI-2010 and uncontrolled asthma}

Among women with current asthma, 23\% had uncontrolled asthma. After adjustment for age (Table 3), only the second tertile of the AHEI-2010 was associated with a lower likelihood of uncontrolled asthma: OR $(95 \% \mathrm{CI})$ was 0.73 (0.56-0.94) for tertile 2, and $0.82(0.64-1.06)$ for tertile 3 , as compared with tertile $1, p$ for trend $=0.19$. After adjustment for potential confounders (model 2), and further adjustment for multimorbidity-related medication profiles (model 3), associations became weaker. Similar findings were reported when using the non-imputed dataset $(n=1,858$; Table 3$)$ or the ACT categorised into three categories (etable 2).

In analyses stratified on BMI, similar associations were reported, and the interaction term between the AHEI-2010 and BMI was not statistically significant (Fig. 3) ( $p$ for interaction $=0.34$ ). Using SEM, we still reported no significant association between the AHEI-2010 and uncontrolled asthma, as well a significant negative relationship between the AHEI-2010 and BMI, and a significant positive association between BMI and uncontrolled asthma (eFigure 2).

After stratification for smoking, associations between the AHEI-2010 and uncontrolled asthma remained of similar magnitude in each category with no statistical significance, except for AHEI-tertile 2 in never smokers (Fig. 3) ( $p$ for interaction $=0.64$ ).

\section{Association between AHEI-2010 and multimorbidity-related medication profiles}

Among women with ever asthma, $44.7 \%$ belonged to the "Few multimorbidity-related medications", 33\% belonged to the "predominantly metabolic multimorbidity-related 
Table 1 Baseline characteristics of women according to quintiles of the AHEI-2010 diet score $(n=12,991)$

\begin{tabular}{|c|c|c|c|c|c|c|c|}
\hline & \multicolumn{5}{|c|}{ AHEI-2010 diet score } & \multirow[b]{2}{*}{$P$ for trend } & \multirow[b]{2}{*}{$P$ for trend ${ }^{\mathrm{a}}$} \\
\hline & Quintile 1 & Quintile 2 & Quintile 3 & Quintile 4 & Quintile 5 & & \\
\hline AHEI-2010 diet score, $\min -\max$ & $13.0-40.4$ & $40.5-45.3$ & $45.4-49.5$ & $49.6-54.3$ & $54.4-77.0$ & & \\
\hline AHEI-2010 diet score & $35.9(3.8)$ & 43.1(1.4) & $47.4(1.2)$ & $51.8(1.3)$ & $58.8(3.7)$ & & \\
\hline \multicolumn{8}{|l|}{ Component score of AHEI-2010 } \\
\hline Vegetables, servings/d & $5.4(2.7)$ & $6.2(2.6)$ & $6.6(2.5)$ & $6.9(2.6)$ & $7.4(2.5)$ & $<0.0001$ & $<0.0001$ \\
\hline Fruits, servings/d & $1.4(0.8)$ & $1.7(0.9)$ & $1.9(1.0)$ & $2.1(1.0)$ & $2.5(1.1)$ & $<0.0001$ & $<0.0001$ \\
\hline Cereal fibres, $\mathrm{g} / \mathrm{d}$ & $2.2(2.5)$ & $2.7(2.9)$ & $3.2(3.2)$ & $3.8(3.4)$ & $4.7(3.7)$ & $<0.0001$ & $<0.0001$ \\
\hline Sugar-sweetened drinks and fruit juice, servings/d & $0.8(0.7)$ & $0.6(0.6)$ & $0.5(0.6)$ & $0.4(0.5)$ & $0.3(0.4)$ & $<0.0001$ & $<0.0001$ \\
\hline Nuts and legumes, servings/d & $0.5(0.5)$ & $0.7(0.6)$ & $0.7(0.7)$ & $0.8(0.7)$ & $1.0(0.8)$ & $<0.0001$ & $<0.0001$ \\
\hline Red and processed meat, servings/d & $1.4(0.6)$ & $1.2(0.6)$ & $1.1(0.5)$ & $1.0(0.5)$ & $0.9(0.5)$ & $<0.0001$ & $<0.0001$ \\
\hline Long-chain n-3 fatty acids, mg/d & $38.8(24.3)$ & $41.9(27.0)$ & $43.4(28.9)$ & $45.2(30.0)$ & $50.3(36.3)$ & $<0.0001$ & $<0.0001$ \\
\hline PUFA, $\%$ of energy & $5.1(1.3)$ & $5.5(1.3)$ & $5.9(1.4)$ & $6.3(1.5)$ & $6.9(1.7)$ & $<0.0001$ & $<0.0001$ \\
\hline Sodium, mg/d & $2,971(841)$ & $2,816(795)$ & $2,729(763)$ & $2,605(719)$ & $2,460(679)$ & $<0.0001$ & $<0.0001$ \\
\hline Alcohol, drinks/d & $2.1(2.2)$ & $1.6(1.7)$ & $1.4(1.4)$ & $1.2(1.1)$ & $1.0(0.8)$ & $<0.0001$ & $<0.0001$ \\
\hline Age (years) & $63.1(6.2)$ & $63.1(6.1)$ & $63.4(6.2)$ & $63.6(6.2)$ & $63.4(5.9)$ & 0.01 & \\
\hline Energy intake (kcal/d) & $2,413(565)$ & $2,345(549)$ & $2,274(525)$ & $2,206(494)$ & $2,166(480)$ & $<0.0001$ & $<0.0001$ \\
\hline Leisure-time physical activity (METs/week) & $58.8(50.7)$ & $61.1(50.4)$ & $61.9(52.1)$ & $60.5(48.1)$ & $63.3(49.2)$ & $\mathbf{0 . 0 3}$ & 0.01 \\
\hline Smoking status & & & & & & $<0.0001$ & $<0.0001$ \\
\hline Never smoker & $1205(46.6)$ & $1291(49.7)$ & $1237(47.8)$ & $1269(49.3)$ & $1324(50.0)$ & & \\
\hline Occasional ex-smoker & $276(10.7)$ & $299(11.5)$ & $311(12.0)$ & 307 (11.9) & $284(10.7)$ & & \\
\hline Regular ex-smoker & $647(25.0)$ & $659(25.4)$ & $722(27.9)$ & $749(29.1)$ & $784(29.6)$ & & \\
\hline Occasional current smoker & $35(1.4)$ & $32(1.2)$ & $30(1.2)$ & $24(1.0)$ & $34(1.3)$ & & \\
\hline Regular current smoker & $172(6.7)$ & $147(5.7)$ & $123(4.8)$ & $83(3.2)$ & $105(3.9)$ & & \\
\hline Missing & $249(9.6)$ & $170(6.5)$ & $162(6.3)$ & $142(5.5)$ & $119(4.5)$ & & \\
\hline Educational level & & & & & & 0.14 & 0.07 \\
\hline$<$ high school diploma & $256(9.9)$ & $251(9.7)$ & $239(9.3)$ & $445(9.4)$ & $498(8.0)$ & & \\
\hline High school to 2-level university & $1257(48.7)$ & $1286(49.5)$ & $1301(50.3)$ & $1343(52.2)$ & $1340(50.5)$ & & \\
\hline 3- to 4-level university & $504(19.5)$ & $471(18.1)$ & $480(18.6)$ & $477(18.5)$ & $517(19.5)$ & & \\
\hline$\geq 5$-level university & $481(18.6)$ & $522(20.1)$ & $483(18.7)$ & 445 (17.3) & $498(18.8)$ & & \\
\hline Missing & $86(3.3)$ & $68(2.6)$ & $82(3.1)$ & $66(2.6)$ & $84(3.2)$ & & \\
\hline Marital status & & & & & & 0.19 & 0.65 \\
\hline No & $438(17.0)$ & $424(16.3)$ & $379(14.7)$ & $400(15.5)$ & $428(16.2)$ & & \\
\hline Yes & 2044 (79) & $2098(80.8)$ & $2112(81.7)$ & $2098(81.5)$ & $2123(80.1)$ & & \\
\hline Missing & $102(4.0)$ & $76(2.9)$ & $94(3.6)$ & $76(3.0)$ & $99(3.7)$ & & \\
\hline Having farmer parents & & & & & & $<0.0001$ & $<0.0001$ \\
\hline No & $2304(89.1)$ & $2253(86.7)$ & $2202(85.2)$ & $2228(86.6)$ & $2249(84.9)$ & & \\
\hline Yes & $206(8.0)$ & $269(10.4)$ & $298(11.5)$ & $278(10.8)$ & $332(12.5)$ & & \\
\hline Missing & $74(2.9)$ & $76(2.9)$ & $85(3.3)$ & $68(2.6)$ & $69(2.6)$ & & \\
\hline$B M I\left(k g / m^{2}\right)$ & & & & & & $<0.0001$ & $<0.0001$ \\
\hline$<20$ & $288(11.1)$ & 309 (11.9) & $312(12.1)$ & $314(12.2)$ & $362(13.6)$ & & \\
\hline $20-24.9$ & $1354(52.4)$ & $1408(54.2)$ & $1435(55.5)$ & $1468(57.0)$ & $1570(59.3)$ & & \\
\hline $25-29.9$ & $716(27.7)$ & $673(25.9)$ & $658(25.5)$ & $628(24.4)$ & $594(22.4)$ & & \\
\hline$\geq 30$ & $226(8.8)$ & $208(8.0)$ & $180(6.9)$ & $164(6.4)$ & $124(4.7)$ & & \\
\hline $\operatorname{BMI}\left(\mathrm{kg} / \mathrm{m}^{2}\right)$ & $24.3(4.1)$ & $24.1(4.0)$ & $24.0(4.0)$ & $23.8(3.7)$ & $23.4(3.5)$ & $<0.0001$ & $<0.0001$ \\
\hline Asthma symptom score ${ }^{\mathrm{a}}$ & & & & & & $<0.0001$ & $<0.0001$ \\
\hline 0 & $1502(58.1)$ & $1540(59.3)$ & $1560(60.3)$ & $1581(61.4)$ & 1704 (64.3) & & \\
\hline 1 & $680(26.3)$ & 733 (28.2) & $693(26.8)$ & $661(25.7)$ & $678(25.6)$ & & \\
\hline 2 & $178(6.9)$ & $170(6.5)$ & $185(7.2)$ & $180(7.0)$ & $129(4.9)$ & & \\
\hline$\geq 3$ & $224(8.7)$ & $155(6.0)$ & $147(5.7)$ & $152(5.9)$ & $139(5.2)$ & & \\
\hline
\end{tabular}


Table 1 (continued)

\begin{tabular}{|c|c|c|c|c|c|c|c|}
\hline & \multicolumn{5}{|c|}{ AHEI-2010 diet score } & \multirow[b]{2}{*}{$P$ for trend } & \multirow[b]{2}{*}{$P$ for trend ${ }^{\mathrm{a}}$} \\
\hline & Quintile 1 & Quintile 2 & Quintile 3 & Quintile 4 & Quintile 5 & & \\
\hline Asthma control test ${ }^{\mathrm{c}}$ & & & & & & 0.20 & 0.13 \\
\hline$>19$ & $490(75.3)$ & & $501(79.2)$ & & $440(76.7)$ & & \\
\hline$\leq 19$ & $161(24.7)$ & & $132(20.8)$ & & $134(23.3)$ & & \\
\hline Multimorbidity-related medication profiles ${ }^{\mathrm{c}}$ & & & & & & 0.07 & $\mathbf{0 . 0 3}$ \\
\hline "Few multimorbidity-related medications" & $510(43.3)$ & & $508(44.0)$ & & $532(46.6)$ & & \\
\hline $\begin{array}{l}\text { "Predominantly allergic multimorbidity-related } \\
\text { medications" }\end{array}$ & $391(33.2)$ & & $380(32.9)$ & & $376(32.9)$ & & \\
\hline $\begin{array}{l}\text { "Predominantly metabolic multimorbidity-related } \\
\text { medications" }\end{array}$ & $276(23.5)$ & & $267(23.1)$ & & $234(20.5)$ & & \\
\hline
\end{tabular}

$P<0.05$ values are presented in bold

Data are presented as $n(\%)$ or mean (SD) unless otherwise stated. $P$ for trend were calculated using the quintile median values

${ }^{\text {a Age-adjusted models }}$

${ }^{b}$ Asthma symptom score: number of respiratory symptoms during the past 12 months: 1) breathless while wheezing; 2) woken up with chest tightness; 3) attack of shortness of breath at rest; 4) attack of shortness of breath after exercise; and 5) woken by attack of shortness of breath. Each item is scored from zero to one and the total asthma symptom score ranges from zero to five [21]

${ }^{\mathrm{c}}$ For ACT and multimorbidity-related medications profiles, distributions are given according to tertiles of the AHEI-2010 diet core (instead of quintiles)

ACT: asthma control test, based on five questions in the last 4 weeks on: 1. activity limitations (does asthma keep you from getting as much done at work, school or at home, "some of the time" to "all of the time"); 2. shortness of breath ("three to six times per week" to "more than once daily"); 3. woken up by asthma symptoms at night ("once per week" to "every night"); 4. use of a $\beta$-agonist inhaler ("two times per week" to "three or more times daily"); and 5. self-rated asthma control ("somewhat controlled" to "not controlled at all"). Each item is scored from one to five and the total ACT score ranges from five to 25. Asthma control was classified into two categories based on ACT score (> 19: controlled vs. $\leqslant 19$ : uncontrolled) [22]

Multimorbidity-related medications profiles: using a clustering method, we previously identified three multimedication profiles among women with asthma: a "Few multimorbidity-related medications" profile, a "Predominantly allergic multimorbidity-related medications" profile, and a "Predominantly metabolic multimorbidity-related medications" profile [23]

Table 2 Association between the AHEI-2010 diet score (quintiles) and the asthma symptom score $(n=12,991)$

\begin{tabular}{|c|c|c|c|c|c|}
\hline & & & Age-adjusted model 1 & $\begin{array}{l}\text { Multivariable- } \\
\text { adjusted model } \\
2^{\mathrm{a}}\end{array}$ & $\begin{array}{l}\text { Multivariable- } \\
\text { adjusted model } \\
3^{\mathrm{b}}\end{array}$ \\
\hline & $N$ & $\begin{array}{l}\text { AHEI- } \\
2010 \text {, mean } \\
(\mathrm{sd})\end{array}$ & MSR (95\% CI) & $\operatorname{MSR}(95 \% \mathrm{CI})$ & $\operatorname{MSR}(95 \% \mathrm{CI})$ \\
\hline AHEI-2010 diet score & 12,991 & & & & \\
\hline Quintile 1 & 2,584 & $35.9(3.8)$ & 1.00 (ref) & 1.00 (ref) & 1.00 (ref) \\
\hline Quintile 2 & 2,598 & $43.1(1.4)$ & $0.91(0.83-0.99)$ & $0.92(0.84-1.00)$ & $0.92(0.85-1.00)$ \\
\hline Quintile 3 & 2,585 & $47.4(1.2)$ & $0.85(0.78-0.93)$ & $0.85(0.78-0.93)$ & $0.87(0.80-0.95)$ \\
\hline Quintile 4 & 2,574 & $51.8(1.3)$ & $0.86(0.79-0.94)$ & $0.87(0.79-0.95)$ & $0.90(0.82-0.98)$ \\
\hline Quintile 5 & 2,650 & $58.8(3.7)$ & $0.77(0.71-0.84)$ & $0.80(0.73-0.88)$ & $0.82(0.75-0.90)$ \\
\hline$P$ for trend & & & $<0.0001$ & $<0.0001$ & $<0.0001$ \\
\hline
\end{tabular}

$P<0.05$ values are presented in bold

MSR mean score ratio

$P$ for trend were calculated using the quintile median values

${ }^{a}$ Multivariable-adjusted model 2 includes age, energy intake, physical activity, smoking, educational level, marital status and having farmer parents

${ }^{\mathrm{b}}$ Multivariable-adjusted model 3 includes model 2 variables (see above) plus ever asthma 
Fig. 2 Associations between quintiles of the AHEI-2010 diet score and the asthma symptom score, stratified according to smoking status, body mass index (BMI) and ever asthma. Models were adjusted for age, energy intake, physical activity, smoking (excepted in models stratified by smoking status), educational level, marital status, and having farmer parents. The first quintile (Q1) serves as reference. Asthma symptom score ranges from 0 to 5
Smoking Status ( $p$ interaction $=\mathbf{0 . 9 8})$

Never smokers

Q1 (ref), $n=1,205$

Q2, $n=1,291$

Q3, $n=1,237$

Q4, $n=1,263$

$\mathrm{Q} 5, \mathrm{n}=1,324$

Ex smokers

Q1 (ref), $n=923$

Q2, $n=958$

Q3, $n=1,033$

Q4, $n=1,056$

$\mathrm{Q} 5, \mathrm{n}=1,068$

Current smokers

Q1 (ref), $n=207$

Q2, $n=179$

$\mathrm{Q} 3, \mathrm{n}=154$

Q4, $n=107$

$Q 5, n=139$

Body mass index $(p$ interaction $=0.14$ )

$<20 \mathrm{~kg} / \mathrm{m}^{2}$

Q1 (ref), $n=288$

Q2, $n=309$

Q3, $n=312$

Q4, $n=314$

$\mathrm{Q} 5, \mathrm{n}=362$

[20-25[ kg/m²

Q1 (ref), $n=1,354$

Q2, $n=1,408$

Q3, $n=1,435$

$\mathrm{Q} 4, \mathrm{n}=1,468$

$\mathrm{Q} 5, \mathrm{n}=1,570$

$\geq 25 \mathrm{~kg} / \mathrm{m}^{2}$

Q1 (ref), $n=942$

Q2, $n=881$

$\mathrm{Q} 3, \mathrm{n}=838$

$Q 4, n=792$

$Q 5, n=718$

Asthma ever ( $p$ interaction $=\mathbf{0 . 2 2})$

No

Q1 (ref), $n=1,773$

$\mathrm{Q} 2, \mathrm{n}=1,754$

Q3, $n=1,774$

Q4, $n=1,848$

$\mathrm{Q} 5, \mathrm{n}=1,836$

Yes

Q1 (ref), $n=597$

Q2, $n=578$

Q3, $n=614$

$Q 4, n=569$

$\mathrm{Q}, \mathrm{n}=541$

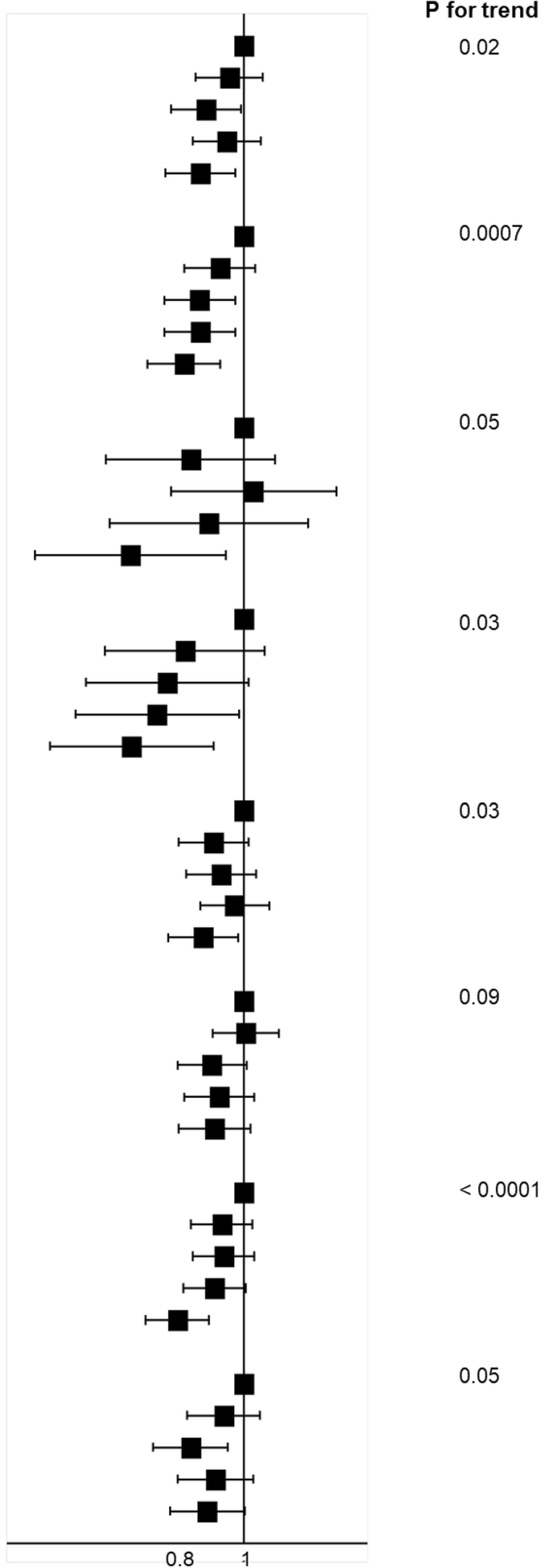

medications" profile, and $22.3 \%$ to the "predominantly allergic multimorbidity-related medications" profile. After adjustment for age (Table 4), women with higher AHEI2010 score were at a lower risk to belong to the "Predominantly metabolic multimorbidity-related medications" profile compared to the "Few multimorbidity-related medications" profile: ORs (95\% CI) were 0.94 (0.76-1.17) for tertile 2 and $0.75(0.60-0.93)$ for tertile 3 vs. tertile 1 ( $p$ trend $=0.01$ ). Results remained similar after further adjustment for potential confounders. By contrast, the AHEI-2010 was not associated with the "predominantly allergic multimorbidity-related medications" profile. 
Table 3 Association between the AHEI-2010 diet score (tertiles) and uncontrolled asthma

\begin{tabular}{|c|c|c|c|c|c|}
\hline & & & Age-adjusted model 1 & $\begin{array}{l}\text { Multivariable- } \\
\text { adjusted model } 2^{\mathrm{b}}\end{array}$ & $\begin{array}{l}\text { Multivariable- } \\
\text { adjusted model } \\
3^{\mathrm{c}}\end{array}$ \\
\hline & $n$ & $\begin{array}{l}\text { AHEI-2010, } \\
\text { mean }(\mathrm{sd})\end{array}$ & OR $(95 \% \mathrm{CI})$ & OR $(95 \% \mathrm{CI})$ & OR $(95 \% \mathrm{CI})$ \\
\hline Uncontrolled asthma (after imputation) ${ }^{\mathrm{a}}$ & 2587 & & & & \\
\hline AHEI-2010 tertile 1 & 895 & $38.3(4.4)$ & 1.00 (ref) & 1.00 (ref) & 1.00 (ref) \\
\hline AHEI-2010 tertile 2 & 884 & $47.4(2.0)$ & $0.73(0.56-0.94)$ & $0.72(0.55-0.94)$ & $0.73(0.55-0.98)$ \\
\hline AHEI-2010 tertile 3 & 808 & $56.1(4.3)$ & $0.82(0.64-1.06)$ & $0.84(0.65-1.10)$ & $0.86(0.65-1.12)$ \\
\hline$P$ for trend & & & 0.11 & 0.19 & 0.24 \\
\hline Uncontrolled asthma (before imputation) & 1858 & & & & \\
\hline AHEI-2010 tertile 1 & 651 & $38.2(4.5)$ & 1.00 (ref) & 1.00 (ref) & 1.00 (ref) \\
\hline AHEI-2010 tertile 2 & 633 & $47.4(2.0)$ & $0.76(0.57-1.00)$ & $0.75(0.57-1.00)$ & $0.76(0.57-1.00)$ \\
\hline AHEI-2010 tertile 3 & 574 & $55.9(4.2)$ & $0.87(0.66-1.14)$ & $0.89(0.67-1.18)$ & $0.92(0.69-1.2)$ \\
\hline$P$ for trend & & & 0.32 & 0.39 & 0.51 \\
\hline
\end{tabular}

$P<0.05$ values are presented in bold

$P$ for trend were calculated using the tertile median values

${ }^{a}$ Analysis after using multiple imputation to estimate ACT missing values, as in previous analyses in this population [40]. See online supplement for details

${ }^{\mathrm{b}}$ Multivariable-adjusted model 2 includes age, energy intake, physical activity, smoking, educational level, marital status and having farmer parents

${ }^{\mathrm{c}}$ Multivariable-adjusted model 3 includes model 2 variables (see above) plus multimorbidity-related medication profiles

Smoking Status $(p$ interaction $=0.60)$

$P$ for trend

Never smokers

$$
\begin{aligned}
& \text { T1 (ref), } n=398 \\
& \text { T2, } n=409 \\
& \begin{array}{l}
\text { T3, } n=382 \\
\text { smokers }
\end{array} \\
& \text { T1 (ref), } n=425 \\
& \text { T2, } n=423 \\
& \text { T3, } n=396
\end{aligned}
$$$$
\text { Ever smokers }
$$

Body mass index ( $p$ interaction $=0.37)$

$$
\begin{gathered}
<25 \mathrm{~kg} / \mathrm{m}^{2} \\
\text { T1 (ref), } \mathrm{n}=488 \\
\mathrm{~T} 2, \mathrm{n}=542 \\
\mathrm{~T} 3, \mathrm{n}=509 \\
\geq 25 \mathrm{~kg} / \mathrm{m}^{2} \\
\mathrm{~T} 1 \text { (ref), } \mathrm{n}=407 \\
\mathrm{~T} 2, \mathrm{n}=342 \\
\text { T3, } \mathrm{n}=299
\end{gathered}
$$

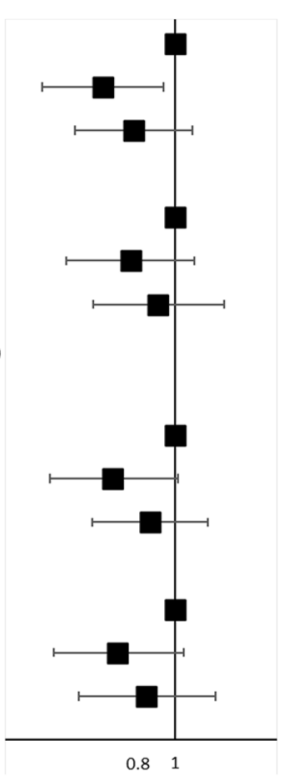

0.20

Fig. 3 Associations between tertiles of the AHEI-2010 diet score and uncontrolled asthma, stratified according to smoking status and BMI. Models were adjusted for age, energy intake, physical activity, smoking (excepted in models stratified by smoking status), educational level, marital status and having farmer parents. The first tertile (T1) serves as reference
After stratification for smoking (Fig. 4), similar associations were reported between the AHEI-2010 and multimorbidity-related medication profiles among never and ever smokers, with no interaction between the AHEI-2010 and the smoking status $(p=0.29$ for the allergic profile, and 0.23 for the metabolic profile).

\section{Discussion}

In this large study of more than 12,000 elderly women, a stronger adherence to a healthy diet evaluated by the AHEI2010 was associated with a lower asthma symptom score, and among women with asthma, with disease characteristics associated with better asthma prognosis. These findings strengthen evidence supporting the promotion of a healthy diet to target reduction in asthma respiratory symptoms among elderly women, and confirm the importance of considering diet in the relation between asthma and comorbidities, especially cardiovascular diseases.

To our knowledge, five studies have investigated the association between the AHEI-2010 and asthma outcomes, among young [39] to middle-aged adults [17, 18, 40, 41], and using a dichotomous [39-41] or a continuous [17, 18] definition of asthma, and they reported mixed findings. The three studies that used a dichotomous definition of asthma, namely wheezing (yes/no), incident asthma (yes/no), or at 
Table 4 Association between the AHEI-2010 diet score (tertiles) and multimorbidity-related medication profiles $(n=3474)$

\begin{tabular}{|c|c|c|c|c|c|c|c|c|c|}
\hline & \multicolumn{9}{|c|}{ Multimorbidity-related medication profiles } \\
\hline & \multicolumn{3}{|c|}{$\begin{array}{l}\text { "Few multimorbidity-related } \\
\text { medications" profile }\end{array}$} & \multicolumn{3}{|c|}{$\begin{array}{l}\text { "Predominantly allergic multimorbidity- } \\
\text { related medications" profile }\end{array}$} & \multicolumn{3}{|c|}{$\begin{array}{l}\text { "Predominantly metabolic multimorbidity- } \\
\text { related medications" profile }\end{array}$} \\
\hline & $n$ & $\begin{array}{l}\text { AHEI- } \\
2010, \text { mean } \\
(\mathrm{sd})\end{array}$ & OR $(95 \% \mathrm{CI})$ & $n$ & $\begin{array}{l}\text { AHEI-2010, m } \\
\text { (sd) }\end{array}$ & OR $(95 \% \mathrm{CI})$ & $n$ & $\begin{array}{l}\text { AHEI-2010, } m \\
(\mathrm{sd})\end{array}$ & OR $(95 \% \mathrm{CI})$ \\
\hline $\begin{array}{l}\text { Age-adjusted } \\
\text { model } 1\end{array}$ & 1550 & & & 1147 & & & 777 & & \\
\hline $\begin{array}{l}\text { AHEI-2010 tertile } \\
1\end{array}$ & 510 & $38.7(4.1)$ & $1.00(\mathrm{ref})$ & 391 & $38.1(4.5)$ & 1.00 (ref) & 276 & $38.1(4.3)$ & 1.00 (ref) \\
\hline $\begin{array}{l}\text { AHEI-2010 tertile } \\
2\end{array}$ & 508 & $47.3(2.0)$ & $1.00(\mathrm{ref})$ & 380 & $47.5(2.1)$ & $0.97(0.80-1.17)$ & 267 & $47.3(2.0)$ & $0.94(0.76-1.17)$ \\
\hline $\begin{array}{l}\text { AHEI-2010 tertile } \\
3\end{array}$ & 532 & $56.4(4.4)$ & 1.00 (ref) & 376 & $56.2(4.3)$ & $0.91(0.75-1.10)$ & 234 & $55.5(4.2)$ & $0.75(0.60-0.93)$ \\
\hline$P$ for trend & & & & & & 0.32 & & & 0.01 \\
\hline $\begin{array}{l}\text { Multivariable- } \\
\text { adjusted model } \\
2^{\mathrm{a}}\end{array}$ & 1550 & & & 1147 & & & 777 & & \\
\hline $\begin{array}{l}\text { AHEI-2010 tertile } \\
1\end{array}$ & 510 & $38.7(4.1)$ & 1.00 (ref) & 391 & $38.1(4.5)$ & 1.00 (ref) & 276 & $38.1(4.3)$ & 1.00 (ref) \\
\hline $\begin{array}{l}\text { AHEI-2010 tertile } \\
2\end{array}$ & 508 & $47.3(2.0)$ & 1.00 (ref) & 380 & $47.5(2.1)$ & $0.99(0.81-1.20)$ & 267 & $47.3(2.0)$ & $0.96(0.77-1.21)$ \\
\hline $\begin{array}{l}\text { AHEI-2010 tertile } \\
3\end{array}$ & 532 & $56.4(4.4)$ & $1.00(\mathrm{ref})$ & 376 & $56.2(4.3)$ & $0.96(0.79-1.17)$ & 234 & $55.5(4.2)$ & $0.80(0.63-1.00)$ \\
\hline$P$ for trend & & & & & & 0.64 & & & 0.05 \\
\hline
\end{tabular}

$P<0.05$ values are presented in bold

$P$ for trend were calculated using the tertile median values

${ }^{\text {a }}$ + Multivariable-adjusted model 2 includes age, energy intake, physical activity, smoking, educational level, marital status and having farmer parents

least one out of three current asthma symptoms (yes/no), reported conflicting results. Using the asthma symptom score, two previous studies have investigated its association with the AHEI-2010 and reported that a healthy diet was associated with lower asthma symptoms [17, 18]. Regarding other dietary scores (a priori approach), the most studied are the Mediterranean diet score based on recommended foods or nutrients for disease prevention (such as the AHEI-2010) and the Dietary Inflammatory Index (DII) which relates to pathophysiological processes relevant to asthma (i.e. inflammation). To our knowledge, only one cross-sectional study reported a positive association between the Mediterranean diet and the asthma symptoms score in adults [18]. For the DII, one case-control [42] and two cross-sectional studies $[41,43]$ investigated associations with asthma in adults, and they all reported that a higher DII was associated with asthma [42] or current asthma [41, 43]. By contrast, using the a posteriori approach to derive data-driven dietary patterns (i.e., statistically derived independently of their relevance to any disease), at least 13 studies have looked at the association between dietary patterns, mostly derived using principal component analysis (PCA), and asthma symptoms or incidence in adults, and they have yielded mixed findings [44-47]. Our current findings are consistent with those based on younger populations and support the likely impact of a healthy diet in the prevention of asthma in elderly women. They extend results obtained from younger population and provide first evidence for the impact of a healthy diet in the prevention of asthma over the life course.

Regarding the impact of an overall healthy diet as a disease modifier, a healthier diet was associated in our study with a lower risk of uncontrolled asthma but the association did not reach statistical significance. Five studies have been published so far, all among middle-aged adults and overall, they reported mixed findings as follows: three studies reported an association between an overall healthy diet and lower uncontrolled asthma [48-50], one reported no association [51], and one reported a borderline significant association in women [18]. Published studies are very heterogeneous in term of tools used to evaluate asthma control as follows: two used the ACT $[18,50]$ and three used the asthma control questionnaire (ACQ) [48, 49, 51]; in terms of tools used to collect dietary data, three used 24-h dietary records [18, 48, 50], and two used a FFQ [49, 51]; and in 


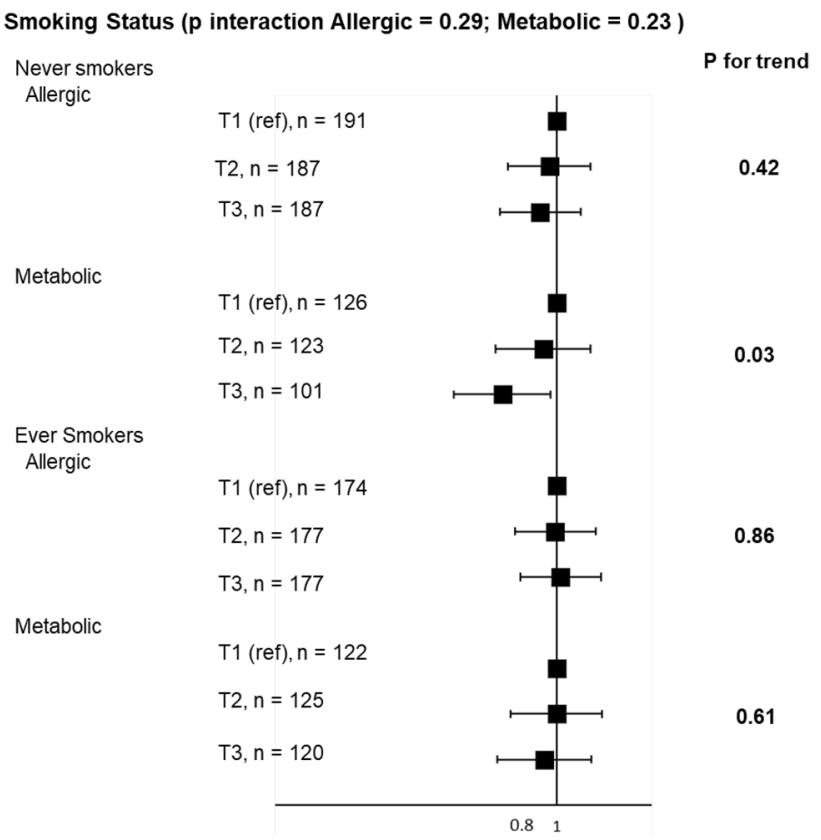

Fig. 4 Associations between tertiles of the AHEI-2010 diet score and multimorbidity-related medication profiles, stratified according to smoking status. Models were adjusted for age, energy intake, physical activity, educational level, marital status and having farmer parents. The first tertile (T1) serves as reference

terms of tools used to estimate the overall diet, one used the Dietary Approaches to Stop Hypertension (DASH) score [48], one used the DII [50], two used the Mediterranean diet score [49, 51], and one used the AHEI-2010 [18]. All five studies used dietary data collected at the same time as asthma control data or in the year before. In our study, diet was evaluated by two validated semi-quantitative food history questionnaires administrated in 1993 and 2005, whereas asthma control was evaluated in 2011. The assessment of diet does not cover the ACT window of exposure and it is likely that participants may have modified their diet between 1993 and 2011. Anyhow, it has been shown that diet remains globally stable in this specific population, namely elderly women with a high level of education [52], and we used the average diet between 1993 and 2005 which is likely more representative of the usual diet as compared to one assessment only. Although diet might be a modifiable risk factor that could be targeted to help reduce asthma exacerbations and reach a good level of asthma control, its potential role on asthma control remains unclear, particularly among elderly women.

Besides allergic-related morbidities, that are common especially in childhood asthma, it has been more recently reported that mechanisms involved in adult-onset asthma also include several metabolic and inflammatory pathways also related to other chronic conditions such as obesity, the metabolic syndrome, type 2 diabetes mellitus, or CVD [53].
Although the underlying mechanisms remain unknown, it has been suggested that asthma and CVD share common risk factors such as smoking, obesity, or more recently reported, air pollution exposure [54], consistent with common etiological pathways. The AHEI-2010 is based on a comprehensive review to identify foods and nutrients that have been consistently associated with lower risks of CVD, cancer, and type 2 diabetes in clinical and epidemiological investigations [16]. The AHEI-2010 also captures additional information on diet quality that may further decrease the risk of metabolic diseases [16]. Our findings provide further evidence for a major role of an unhealthy diet as a common risk factor between asthma and CVD. A better understanding of the role of a healthy diet could lead to risk management strategies for patients with asthma to reduce their CVD risk.

Several hypotheses and mechanisms have been raised to explain the role of diet in asthma, including oxidative stress and inflammation, and more recently, vitamin D, epigenetic regulation, and imbalance in the gut microbiome [55]. Asthma is a chronic inflammatory disease of the airways, and endogenous reactive oxygen species have been implicated in its pathogenesis [56]. It has been extensively reported that a better quality diet (high in fruit, vegetables, whole grains, and legumes as reflected by a high AHEI2010) is associated with lower inflammatory biomarkers [57], and more recently with a reduction in short-chain fatty acids [58] (produced by bacteria in the gut during fermentation of fibre from dietary plant matter) known to reduce airway inflammation [59]. In this manner, a dietary intervention based on a fibre-rich healthy diet might be relevant for both primary and secondary prevention of asthma.

Diet, physical activity, and body composition are nutritional factors that are not only closely interrelated (at a given time $t$ ) but also time-dependent, which makes it difficult to disentangle their separate effects on asthma outcome [60]. Regarding interrelations (at a given time $t$ ), although obesity can result from multiple factors (e.g., genetic predispositions, certain disease status, or medication use), it is most often a result of unhealthy lifestyle, including excessive dietary energy intakes and insufficient physical activity [61]. It has been shown that individuals with lower overall diet quality have higher risk of obesity [36]. The established evidence that links diet to obesity and that links obesity to asthma [10] and asthma control [62] can illustrate the role of obesity as a potential mediator in the diet-asthma association [60]. In this context, several studies provided results with and, in addition, without adjustment for BMI $[63,64]$ but it could lead to biased results [65]. Some novel analyzing approaches, such as the counterfactual approach, provide a new tool to face the above issues in mediation analysis [66]. To our knowledge, only two studies were conducted in the context of nutritional factors and asthma, suggesting that BMI partly mediates the association between high cured meat intake and worsening 
asthma symptoms over time [67], but does not mediate the association between overall diet quality-assessed using the AHEI-2010-and improved asthma symptoms [17]. From a longitudinal perspective, interrelations between nutritional factors and asthma are also time-dependent. Indeed, in addition to the potential role of each nutritional factor at a given time $t$ on asthma at a time $t+1$, asthma at time $t-1$ may have modified nutritional factors at time $t$ (e.g., asthma can lead to a decrease in physical activity), and each nutritional factor at time $t-1$ may have modified another nutritional factor at time $t$ (e.g., overweight/obesity can lead to modifying dietary and/ or physical activity behaviours). To our knowledge, only one study has been conducted in the context of the time-dependent associations between physical activity, BMI and asthma (also using data from the $\mathrm{E} 3 \mathrm{~N}$ study) and suggested an independent causal deleterious effect of overweight and obesity on current asthma, but no independent causal effect of physical activity on current asthma [30]. Although longitudinal data are warranted to fully address these issues, our models stratified according to BMI yielded to similar associations between diet and asthma outcomes, and estimates obtained from SEM and those obtained from standard models are very close, showing that BMI is unlikely a major modifier or mediator in the association between diet with asthma outcomes.

Our study has several strengths and limitations. First, our analysis was cross-sectional. However, our findings are based on a large sample size, which allows accounting for several potential confounders and performing stratified analyses to address the robustness of the findings. Secondly, diet was evaluated in 1993 and 2005, and asthma in 2011. Although participants may have modified their diet between 1993 and 2011, it has been shown that the diet remains globally stable in this specific population of elderly women with a high level of education [52]. Although a substantial proportion of women did not complete the ACT (28\%), analyses with and without imputed data yielded similar results. Besides, associations were consistent in several subpopulations and after adjustment for many potential confounders. In addition, we used validated tools to estimate asthma symptoms [24, 25] and asthma control [26] as well as the diet [68]. Secondly, we acknowledge that the main source of disease misclassification among this population of elderly women is probably misdiagnosis of COPD, and that potential overlap between asthma and COPD may have contributed to the association between the AHEI-2010 and asthma. However, we used the asthma symptom score that measures specific symptoms of asthma (and not of COPD) rather than a dichotomous definition of asthma which is more likely to include COPD patients. Moreover, similar associations were observed whatever the smoking status, especially among never smokers who are less likely to suffer from COPD. We also acknowledge that the association between a healthy diet and the "Predominantly metabolic multimorbidity-related medications" profile might be due in part, to obesity. Indeed, obesity (e.g., BMI $\geq 30 \mathrm{~kg} / \mathrm{m}^{2}$ ) was included in the LCA to identify asthma groups, and whereas the "Few multimorbidity-related medications" profile and the "Predominantly allergic multimorbidity-related medications" include respectively $3.4 \%$ and $1.5 \%$ of obese women, the "Predominantly metabolic multimorbidity-related medications" profile includes $34 \%$ of obese women. Finally, the relative homogeneity of the studied population (e.g., elderly women with mostly high educational levels) actually helps with causal inferences about the relation between healthy diet and asthma outcomes because the comparability of the high and low dietary score groups will be higher than in a more heterogeneous populations (i.e., less potential for residual confounding).

In this elderly female population, we observed that a healthier dietary intake was associated with lower asthma symptoms, and among women with asthma, lower risk to belong to a metabolic multimorbidity-related medication profile. Overall, our findings show that a healthy diet may play an important role in the prevention and management of asthma over the life course. There is a need for longitudinal studies and RCTs to help understand better the role of the AHEI-2010 diet for the primary and secondary prevention of asthma among elderly. More studies are also warranted to better understand the role of a healthy diet as a common risk factor for patients with asthma to better reduce their CVD risk, which could lead to risk management strategies among those patients. Lastly, as the investigation of nutritional factors as a whole (diet, physical activity, obesity) is highly relevant in the etiology of asthma and its control, both in terms of understanding the underlying mechanisms and in terms of guiding efficient multidimensional public health interventions, there is a crucial need for further prospective studies to address this issue.

Supplementary Information The online version contains supplementary material available at https://doi.org/10.1007/s00394-022-02815-0.

Acknowledgements The authors would like to thank the E3N team and especially M Fangon, M Niravong, LA Hoang, M Valdenaire, S Eltaief, R Gomes, F Wilm, C Kernaleguen, W Tello, C Laplanche, P Gerbouin-Rérolle, R Chaït, G Esselma, and F Clavel-Chapelon (Inserm U1018 CESP, Villejuif, France) for the implementation and management of the E3N study. They are indebted to all participants, without whom the study would not have been possible, for their high involvement in the E3N study.

Author contributions WAH, MCB and RV designed and conducted the research; WAH, AB, SC, OD, NL, NLM, BL, CM, VS, MCB and RV provided essential reagents or provided essential materials; WAH and RV analysed data or performed statistical analysis; WAH, MCB and RV wrote the manuscript and had primary responsibility for final content; WAH, AB, OD, VS, MCB and RV were involved in interpreting the results and editing the manuscript for important intellectual content; All authors read, edited and approved the final manuscript. 
Funding This work was supported by the Institut pour la Recherche en Santé Publique (IReSP/JPM/MG-2013-0189), and of the joint help of Direction Générale de la Santé (DGS), the Mission recherche de la Direction de la Recherche, des Etudes, de l'Evaluation et des Statistiques (Mire-DREES), the Caisse nationale d'assurance maladie des travailleurs salariés (CNAMTS), Régime Social des Indépendants (RSI) \& Caisse nationale de solidarité pour l'autonomie (CNSA). The E3N-E4N cohort is supported by the Mutuelle Générale de l'Education Nationale (MGEN); the French League against Cancer (LNCC); Gustave Roussy; and the French Research Agency (ANR grant, ANR-10COHO-0006). WHA was supported by a doctoral fellowship from the Ecole Doctorale de Santé Publique, Paris-Saclay University, France.

Availability of data and material Requests for access to data, statistical code, questionnaires, and technical processes may be made by contacting the corresponding author at marie-christine.boutron@gustaveroussy.fr.

\section{Declarations}

Conflict of interest All authors have completed the ICMJE Form for Disclosure of Potential Conflicts of Interest. None were reported except by Dr. Chanoine who reports non-financial support from Novartis, non-financial support from Astellas, non-financial support from Boehringer Ingelheim, outside the submitted work.

Code availability Statistical Analysis Software (SAS) were used.

Ethics approval The E3N study was authorized by the French National Commission for Data Protection and Privacy (CNIL n $\left.{ }^{\circ} 106.246\right)$. E3N data enrichment with the MGEN database was granted ethical approval (CCTIRS $\left.n^{\circ} 13.794\right)$ and was authorized by the CNIL ( ${ }^{\circ} 327346$ V14).

Consent to participate All participants signed informed consent in compliance with the rules of the French National Commission for Computed Data and Individual Freedom (Commission Nationale Informatique et Libertés).

Consent for publication All participants signed informed consent in compliance with the rules of the French National Commission for Computed Data and Individual Freedom (Commission Nationale Informatique et Libertés).

Open Access This article is licensed under a Creative Commons Attribution 4.0 International License, which permits use, sharing, adaptation, distribution and reproduction in any medium or format, as long as you give appropriate credit to the original author(s) and the source, provide a link to the Creative Commons licence, and indicate if changes were made. The images or other third party material in this article are included in the article's Creative Commons licence, unless indicated otherwise in a credit line to the material. If material is not included in the article's Creative Commons licence and your intended use is not permitted by statutory regulation or exceeds the permitted use, you will need to obtain permission directly from the copyright holder. To view a copy of this licence, visit http://creativecommons.org/licenses/by/4.0/.

\section{References}

1. von Mutius E, Smits HH (2020) Primary prevention of asthma: from risk and protective factors to targeted strategies for prevention. Lancet 396:854-866. https://doi.org/10.1016/S01406736(20)31861-4
2. Braido F, Brusselle G, Guastalla D et al (2016) Determinants and impact of suboptimal asthma control in Europe: the INTERNATIONAL CROSS-SECTIONAL AND LONGITUDINAL ASSESSMENT ON ASTHMA CONTROL (LIAISON) study. Respir Res 17:51. https://doi.org/10.1186/s12931-016-0374-z

3. Fuhlbrigge A, Reed ML, Stempel DA et al (2009) The status of asthma control in the U.S. adult population. Allergy Asthma Proc 30:529-533. https://doi.org/10.2500/aap.2009.30.3276

4. Venter C, Agostoni C, Arshad SH et al (2020) Dietary factors during pregnancy and atopic outcomes in childhood: a systematic review from the European Academy of Allergy and Clinical Immunology. Pediatr Allergy Immunol 31:889-912. https://doi. org/10.1111/pai.13303

5. Dunn RM, Busse PJ, Wechsler ME (2018) Asthma in the elderly and late-onset adult asthma. Allergy 73:284-294. https://doi.org/ 10.1111/all.13258

6. Battaglia S, Benfante A, Spatafora M, Scichilone N (2016) Asthma in the elderly: a different disease? Breathe (Sheff) 12:18 28. https://doi.org/10.1183/20734735.002816

7. Curto E, Crespo-Lessmann A, González-Gutiérrez MV et al (2019) Is asthma in the elderly different? Functional and clinical characteristics of asthma in individuals aged 65 years and older. Asthma Res Pract 5:2. https://doi.org/10.1186/s40733-019-0049-x

8. Yáñez A, Cho S-H, Soriano JB et al (2014) Asthma in the elderly: what we know and what we have yet to know. World Allergy Organ J 7:1-16. https://doi.org/10.1186/1939-4551-7-8

9. Baptist AP, Hamad A, Patel MR (2014) Older women with asthma: special challenges in treatment and self-management. Ann Allergy Asthma Immunol 113:125-130. https://doi.org/10. 1016/j.anai.2014.05.013

10. Peters U, Dixon AE, Forno E (2018) Obesity and asthma. J Allergy Clin Immunol 141:1169-1179. https://doi.org/10.1016/j. jaci.2018.02.004

11. Camargo CA, Weiss ST, Zhang S et al (1999) Prospective study of body mass index, weight change, and risk of adult-onset asthma in women. Arch Intern Med 159:2582-2588. https://doi.org/10. 1001/archinte.159.21.2582

12. van der Plaat DA (2020) Mendelian randomisation supports causal link between obesity and asthma. Thorax 75:194-195. https://doi. org/10.1136/thoraxjnl-2019-214164

13. Song W-J, Cho S-H (2015) Challenges in the management of asthma in the elderly. Allergy Asthma Immunol Res 7:431-439. https://doi.org/10.4168/aair.2015.7.5.431

14. Kankaanranta H, Kauppi P, Tuomisto LE, Ilmarinen P (2016) Emerging comorbidities in adult asthma: risks, clinical associations, and mechanisms. Mediat Inflamm 2016:1-23. https://doi. org/10.1155/2016/3690628

15. Cespedes EM, Hu FB (2015) Dietary patterns: from nutritional epidemiologic analysis to national guidelines. Am J Clin Nutr 101:899-900. https://doi.org/10.3945/ajcn.115.110213

16. Chiuve SE, Fung TT, Rimm EB et al (2012) Alternative dietary indices both strongly predict risk of chronic disease123. J Nutr 142:1009-1018. https://doi.org/10.3945/jn.111.157222

17. Li Z, Kesse-Guyot E, Dumas O et al (2017) Longitudinal study of diet quality and change in asthma symptoms in adults, according to smoking status. Br J Nutr 117:562-571. https://doi.org/10.1017/ S0007114517000368

18. Andrianasolo RM, Kesse-Guyot E, Adjibade M et al (2018) Associations between dietary scores with asthma symptoms and asthma control in adults. Eur Respir J. https://doi.org/10.1183/ 13993003.02572-2017

19. Pekkanen J, Sunyer J (2008) Problems in using incidence to analyze risk factors in follow-up studies. Eur J Epidemiol 23:581584. https://doi.org/10.1007/s10654-008-9280-0 
20. Carter P, Lagan J, Fortune C et al (2019) Association of cardiovascular disease with respiratory disease. J Am Coll Cardiol 73:2166-2177. https://doi.org/10.1016/j.jacc.2018.11.063

21. Stampfer MJ, Hu FB, Manson JE et al (2000) Primary prevention of coronary heart disease in women through diet and lifestyle. N Engl J Med 343:16-22. https://doi.org/10.1056/NEJM200007 063430103

22. Clavel-Chapelon F, van Liere MJ, Giubout C et al (1997) E3N, a French cohort study on cancer risk factors. E3N Group. Etude Epidémiologique auprès de femmes de l'Education Nationale. Eur J Cancer Prev 6:473-478

23. Lucas F, Niravong M, Villeminot $S$ et al (1995) Estimation of food portion size using photographs: validity, strengths, weaknesses and recommendations. J Hum Nutr Diet 8:65-74. https://doi.org/ 10.1111/j.1365-277X.1995.tb00296.x

24. Pekkanen J, Sunyer J, Anto JM et al (2005) Operational definitions of asthma in studies on its aetiology. Eur Respir J 26:28-35. https://doi.org/10.1183/09031936.05.00120104

25. Sunyer J, Pekkanen J, Garcia-Esteban R et al (2007) Asthma score: predictive ability and risk factors. Allergy 62:142-148. https://doi.org/10.1111/j.1398-9995.2006.01184.x

26. Schatz M, Sorkness CA, Li JT et al (2006) Asthma Control Test: reliability, validity, and responsiveness in patients not previously followed by asthma specialists. J Allergy Clin Immunol 117:549556. https://doi.org/10.1016/j.jaci.2006.01.011

27. Dumas O, Wiley AS, Quinot C et al (2017) Occupational exposure to disinfectants and asthma control in US nurses. Eur Respir J 50:1700237. https://doi.org/10.1183/13993003.00237-2017

28. Chanoine S, Sanchez M, Pin I et al (2018) Multimorbidity medications and poor asthma prognosis. Eur Respir J. https://doi.org/10. 1183/13993003.02114-2017

29. Agence Nationale de Securite Sanitaire (ANSES) (2013) Table de composition nutritionnelle des aliments Ciqual. In: CIQUAL. https://ciqual.anses.fr/. Accessed 22 Nov 2021

30. Bédard A, Serra I, Dumas O et al (2017) Time-dependent associations between body composition, physical activity, and current asthma in women: a marginal structural modeling analysis. Am J Epidemiol 186:21-28. https://doi.org/10.1093/aje/kwx038

31. Varraso R, Oryszczyn MP, Mathieu N et al (2012) Farming in childhood, diet in adulthood and asthma history. Eur Respir J 39:67-75. https://doi.org/10.1183/09031936.00115010

32. WHO Consultation on Obesity (1997) Obesity: preventing and managing the global epidemic: report of a WHO. World Health Organization, Geneva

33. Jacquemin B, Sunyer J, Forsberg B et al (2009) Association between modelled traffic-related air pollution and asthma score in the ECRHS. Eur Respir J 34:834-842. https://doi.org/10.1183/ 09031936.00138208

34. Temam S, Chanoine S, Bédard A et al (2019) Low socioeconomic position and neighborhood deprivation are associated with uncontrolled asthma in elderly. Respir Med 158:70-77. https://doi.org/ 10.1016/j.rmed.2019.09.010

35. Boulet L-P (2013) Asthma and obesity. Clin Exp Allergy 43:8-21. https://doi.org/10.1111/j.1365-2222.2012.04040.x

36. Boggs DA, Rosenberg L, Rodríguez-Bernal CL, Palmer JR (2013) Long-term diet quality is associated with lower obesity risk in young African American women with normal BMI at baseline. J Nutr 143:1636-1641. https://doi.org/10.3945/jn.113.179002

37. Bédard A, Dumas O, Kauffmann F, et al (2012) Potential confounders in the asthma-diet association: how causal approach could help? Allergy 67:1461-1462; author reply 1462-1463. https://doi.org/10.1111/all.12025

38. VanderWeele TJ (2012) Invited commentary: structural equation models and epidemiologic analysis. Am J Epidemiol 176:608612. https://doi.org/10.1093/aje/kws213
39. Menezes AMB, Schneider BC, Oliveira VP et al (2020) Longitudinal association between diet quality and asthma symptoms in early adult life in a Brazilian birth cohort. J Asthma Allergy 13:493-503. https://doi.org/10.2147/JAA.S261441

40. Varraso R, Chiuve SE, Fung TT et al (2015) Alternate Healthy Eating Index 2010 and risk of chronic obstructive pulmonary disease among US women and men: prospective study. BMJ 350:h286. https://doi.org/10.1136/bmj.h286

41. Han Y-Y, Jerschow E, Forno E et al (2020) Dietary patterns, asthma, and lung function in the hispanic community health study/ study of Latinos. Ann Am Thorac Soc 17:293-301. https://doi. org/10.1513/AnnalsATS.201908-629OC

42. Wood LG, Shivappa N, Berthon BS et al (2015) Dietary inflammatory index is related to asthma risk, lung function and systemic inflammation in asthma. Clin Exp Allergy 45:177-183. https://doi. org/10.1111/cea.12323

43. Han Y-Y, Forno E, Shivappa N et al (2018) The Dietary inflammatory index and current wheeze among children and adults in the United States. J Allergy Clin Immunol Pract 6:834-841.e2. https://doi.org/10.1016/j.jaip.2017.12.029

44. Takaoka M, Norback D (2008) Diet among Japanese female university students and asthmatic symptoms, infections, pollen and furry pet allergy. Respir Med 102:1045-1054. https://doi.org/10. 1016/j.rmed.2008.01.023

45. Lv N, Xiao L, Ma J (2014) Dietary pattern and asthma: a systematic review and meta-analysis. J Asthma Allergy 7:105-121. https://doi.org/10.2147/JAA.S49960

46. Bédard A, Garcia-Aymerich J, Sanchez M et al (2015) Confirmatory factor analysis compared with principal component analysis to derive dietary patterns: a longitudinal study in adult women. J Nutr 145:1559-1568. https://doi.org/10.3945/jn.114. 204479

47. Brigham EP, Steffen LM, London SJ et al (2018) Diet pattern and respiratory morbidity in the atherosclerosis risk in communities study. Ann Am Thorac Soc 15:675-682. https://doi.org/10.1513/ AnnalsATS.201707-5710C

48. Ma J, Strub P, Lv N et al (2016) Pilot randomised trial of a healthy eating behavioural intervention in uncontrolled asthma. Eur Respir J 47:122-132. https://doi.org/10.1183/13993003.00591-2015

49. Barros R, Moreira A, Fonseca J et al (2008) Adherence to the Mediterranean diet and fresh fruit intake are associated with improved asthma control. Allergy 63:917-923. https://doi.org/ 10.1111/j.1398-9995.2008.01665.x

50. Özbey Ü, Uçar A, Shivappa N, Hebert JR (2019) The relationship between dietary inflammatory index, pulmonary functions and asthma control in asthmatics. Iran J Allergy Asthma Immunol 18:605-614. https://doi.org/10.18502/ijaai.v18i6.2173

51. Sexton P, Black P, Metcalf $P$ et al (2013) Influence of mediterranean diet on asthma symptoms, lung function, and systemic inflammation: a randomized controlled trial. J Asthma 50:75-81. https://doi.org/10.3109/02770903.2012.740120

52. Willet W (1998) Nutritional epidemiology, 2nd edn. Oxford University Press, New York

53. Tattersall MC, Guo M, Korcarz CE et al (2015) Asthma predicts cardiovascular disease events: the multi-ethnic study of atherosclerosis. Arterioscler Thromb Vasc Biol 35:1520-1525. https:// doi.org/10.1161/ATVBAHA.115.305452

54. Jeong A, Fiorito G, Keski-Rahkonen P et al (2018) Perturbation of metabolic pathways mediates the association of air pollutants with asthma and cardiovascular diseases. Environ Int 119:334-345. https://doi.org/10.1016/j.envint.2018.06.025

55. Guilleminault L, Williams EJ, Scott HA et al (2017) Diet and asthma: is it time to adapt our message? Nutrients. https://doi.org/ $10.3390 /$ nu9111227 
56. Barnes PJ (1990) Reactive oxygen species and airway inflammation. Free Radic Biol Med 9:235-243. https://doi.org/10.1016/ 0891-5849(90)90034-g

57. Fung TT, McCullough ML, Newby PK et al (2005) Diet-quality scores and plasma concentrations of markers of inflammation and endothelial dysfunction. Am J Clin Nutr 82:163-173. https://doi. org/10.1093/ajen.82.1.163

58. De Filippis F, Pellegrini N, Vannini L et al (2016) High-level adherence to a Mediterranean diet beneficially impacts the gut microbiota and associated metabolome. Gut 65:1812-1821. https://doi.org/10.1136/gutjnl-2015-309957

59. Trompette A, Gollwitzer ES, Yadava K et al (2014) Gut microbiota metabolism of dietary fiber influences allergic airway disease and hematopoiesis. Nat Med 20:159-166. https://doi.org/10.1038/ nm. 3444

60. Bédard A, Li Z, Ait-hadad W et al (2021) The role of nutritional factors in asthma: challenges and opportunities for epidemiological research. Int J Environ Res Public Health 18:3013. https://doi. org/10.3390/ijerph18063013

61. Hruby A, Manson JE, Qi L et al (2016) Determinants and consequences of obesity. Am J Public Health 106:1656-1662. https:// doi.org/10.2105/AJPH.2016.303326

62. Juel CT-B, Ali Z, Nilas L, Ulrik CS (2012) Asthma and obesity: does weight loss improve asthma control? a systematic review. J Asthma Allergy 5:21-26. https://doi.org/10.2147/JAA.S32232
63. Mekary RA, Giovannucci E, Cahill L et al (2013) Eating patterns and type 2 diabetes risk in older women: breakfast consumption and eating frequency. Am J Clin Nutr 98:436-443. https://doi.org/ 10.3945/ajen.112.057521

64. Ley SH, Sun Q, Willett WC et al (2014) Associations between red meat intake and biomarkers of inflammation and glucose metabolism in women. Am J Clin Nutr 99:352-360. https://doi.org/10. 3945/ajen.113.075663

65. MacKinnon DP, Fairchild AJ, Fritz MS (2007) Mediation analysis. Annu Rev Psychol 58:593-614. https://doi.org/10.1146/annurev. psych.58.110405.085542

66. Valeri L, Vanderweele TJ (2013) Mediation analysis allowing for exposure-mediator interactions and causal interpretation: theoretical assumptions and implementation with SAS and SPSS macros. Psychol Methods 18:137-150. https://doi.org/10.1037/a0031034

67. Li Z, Rava M, Bédard A et al (2017) Cured meat intake is associated with worsening asthma symptoms. Thorax 72:206-212. https://doi.org/10.1136/thoraxjnl-2016-208375

68. van Liere MJ, Lucas F, Clavel F et al (1997) Relative validity and reproducibility of a French dietary history questionnaire. Int J Epidemiol 26(Suppl 1):S128-136. https://doi.org/10.1093/ije/26. suppl_1.s128 